\title{
THE PRECORDIAL ELECTROCARDIOGRAM IN INCOMPLETE RIGHT BUNDLE BRANCH BLOCK
}

\author{
Joseph M. Barker, M.D., * Washington, D. C., and Fernando \\ Valencia, M.D., Bogota, Colombia
}

\section{INTRODUCTION}

$T^{N} 1917$ Rothberger and Winterberg ${ }^{1}$ published an electrocardiographic record 1 which depicts the gradual clearing of a defect in conduction affecting the right branch of the bundle of His. An attempt to cut this structure in the course of an experiment on a dog blocked it only temporarily. Fortunately, one of the tracings taken spanned the period during which the injured bundle gradually recovered its conductivity. The investigators recognized that the central complexes of this record represent incomplete right bundle branch block. They are transitional in form between the preceding complexes, which are characteristic of complete block, and the subsequent complexes, which are of normal outline.

Some years later, Wilson and Herrmann, ${ }^{2}$ without being aware of this earlier work, carried out an extensive experimental investigation in which the canine dextrocardiogram and levocardiogram were superimposed in varying time relations by a number of different methods. By producing right bundle branch block and then stimulating the anterior wall of the right ventricle just after the normal excitation wave had reached the left, they were able to produce at will complexes representing a delay in right ventricular activation of any magnitude less than that which occurs in complete right bundle branch block. Such complexes are identical with those of complete right bundle branch block with regard to the parts of the QRS wave written before excitation of the right ventricle begins; that is to say, before the excitation wave spreads to muscle normally excited via the right Purkinje plexus. They are transitional between bundle branch block complexes and normal complexes with regard to the length of the QRS interval and the form of the T wave.

The present report deals with the description, classification, and interpretation of clinical electrocardiograms which are intermediate, with regard to the form of the ventricular complex, between normal tracings and those which represent complete right bundle branch block, and which display a QRS interval measuring less than 0.12 second in the limb leads. We have attempted to establish criteria for the diagnosis of incomplete right bundle branch block and to

From the Department of Internal Medicine, University of Michigan Medical School.

The material upon which this article was based was collected with the aid of grants to $F$. N. Wilson from the Horace H. Rackham School of Graduate Studies and the S. S. Kresge Foundation.

*Work dune as Clinical Fellow of the American College of Physicians for the year 1946. 
learn something about its incidence and its clinical significance. Incomplete left bundle branch block has not been included in our study because of the difficulty of distinguishing the electrocardiographic changes which it produces from those that accompany enlargement of the left ventricle.

\section{MATERIAL AND METHODS}

The tracings studied were selected from a group of 39,778 electrocardiograms taken over a period of fifteen years. Among these we found 1,123 instances in which a definite or tentative diagnosis of a defect in intraventricular conduction of one kind or another had been made. We then examined those patients in whom both standard limb leads and multiple precordial leads had been taken. Since precordial leads are not taken routinely in this laboratory, we also investigated the accuracy of the impressions based on the standard and unipolar linb leads, which are taken in every case. There were 150 instances in which the extremity leads suggested that incomplete right bundle branch block might be present. In thirty-seven of these the precordial leads showed no evidence of a defect in intraventricular conduction. In the remaining 113 cases, the form of the QRS complexes of the leads from the right side of the precordium supported in a greater or lesser measure the view that activation of the right ventricle was abnormally delayed.

The limb leads considered suggestive of incomplete right bundle branch block displayed a QRS interval measuring 0.08 second or more, but less than 0.12 second, and a conspicuous broad $S$ wave in Lead I. In some instances of this kind, the mean electrical axis was deviated to the left so that the electrocardiographic pattern bore a superficial resemblance to that produced by left ventricular enlargement and by incomplete left bundle branch block. In all such instances there were invariably small $Q$ and $S$ waves, as well as a dominant $R$ deflection in Iead $I$. The presence of both a primary and a secondary $R$ wave in the unipolar right arm lead (Lead $V_{R}$ ) was thought at first to be of value in detecting cases of incomplete right bundle branch block, but further investigation did not strongly support this impression.

One hundred seventy-two cases of complete right bundle branch block diagnosed on the basis of the changes in the precordial leads, were also reviewed in order to ascertain whether the variations in electrocardiographic pattern observed in incomplete right bundle branch block are or are not similar to those that occur when the block is complete.

\section{CLASSIFICATION}

Cases of incomplete right bundle branch block associated with myocardial infarction and with pulmonary embolism will be considered separately. The basis for the classification of the rest of our material has been the configuration of the QRS group in the leads from the right side of the precordium. The groups, subgroups, and classes distinguished are listed below. A primary $\mathrm{R}$ and a late $R^{\prime}$ deflection were present in one or more of Leads $V_{1}, V_{2}$, and $V_{\mathrm{E}}$ in all cases 
except those in which a diagnosis of anterior infarction had been made, and one additional case which has been placed alone in Group VII.

Group I.- The R and $\mathrm{R}^{\prime}$ waves of Lead $\mathrm{V}_{1}$ are both small and of nearly the same size. 'The $\mathrm{R}$ ' deflection does not exceed $5.0 \mathrm{~mm}$. in height. If an $\mathrm{S}$ wave is present it is not over $5.0 \mathrm{~mm}$. in depth (Fig. $7, A$ ). This group contains twenty-eight cases.

Group II. - The primary and secondary $R$ waves of $L e a d V_{1}$ are separated by a deep $S$ deflection alway's more and usually much more than $5.0 \mathrm{~mm}$. in depth. This group contains twenty-two cases, which have been placed in two subgroups as follows:

$A$. The $\mathrm{R}$ and $\mathrm{R}^{\prime}$ waves are both small and of about the same voltage (Fig. $7, B$ ). This subgroup contains seventeen cases.

$B$. The $\mathrm{R}$ wave is small, but $\mathrm{R}^{\prime}$ is between 5.0 and $10 \mathrm{~mm}$. in height (Fig. $7, C)$. This subgroup contains five cases.

Group III.-The initial $\mathrm{R}$ wave is small and $\mathrm{R}^{\prime}$ is at least 6.0 and usually more than $10 \mathrm{~mm}$. in height. This group contains thirty cases. On the basis of the behavior of the two $\mathrm{R}$ deflections as the precordial electrode was moved to the left, they were divided in to the following four subgroups:

$A$. 'The $\mathrm{R}^{\prime}$ wave is largest in Lead $\mathrm{V}_{1}$ or Lead $V_{2}$, becomes smaller with each successive lead, and is usually absent or inconspicuous in Lead $V_{3}$ or Lead $V_{4}$. In the leads from the left side of the precordium the $R$ deflection is relatively small (Fig. 7,E). This subgroup contains eleven cases.

$B$. The tracings of this subgroup are similar to those of the preceding with regard to the size of the $R^{\prime}$ wave, but there are small initial $R$ deflections and very deep $S$ waves in the leads from the central part of the precordium, that is, in one or more of Leads $V_{2}$ to $V_{5}$. There are large $R^{\prime}$ waves in the leads from the extreme right side of the precordium and large $R$ waves in the leads from the extreme left side of the precordium, but small $\mathrm{R}$ and deep $\mathrm{S}$ waves in the other precordial leads (Fig. 7,F). This subgroup contains eight cases.

C. The $R^{\prime}$ deflection is conspicuous only in Lead $V_{1}$ or in Leads $V_{1}$ and $V_{2}$. The initial $R$ wave grows rapidly with each succeeding lead and is very tall in the leads from the extreme left side of the precordium. The transitional zone, yielding complexes intermediate in form between those obtained from the extreme right side and those obtained from the extreme left side of the precordium, is unusually far to the right (Fig. 7,G). This subgroup contains six cases.

$D$. As the exploring electrode is shifted to the left, the size of the $\mathrm{R}^{\prime} \mathrm{de}$ creases less rapidly than in subgroups $A, B$, and $C$, and is tall in the first three, four, or even five precordial leads. Instead of being replaced by an $S$ wave in the leads from the transitional zone, it appears to approach the $\mathrm{R}$ deflection and become fused with it (Fig. 7,H). This subgroup contains six cases.

Group IV. This group includes cases of incomplete right bundle branch block associated with right ventricular hypertrophy. These are discussed in a separate section.

Group V. This group contains eleven cases of myocardial infarction. 
Group VI. This group contains two cases of pulmonary embolism.

Group VII. This group contains only one case. All the precordial leads yielded complexes which are transitional in form (Fig. 9).

Our cases were also classified on the basis of the number of precordial leads showing evidence of a conduction defect suggestive of incomplete right bundle branch block, as follows:

Class a.-In forty-seven cases changes of the kind in question were present in Leads $V_{1}, V_{2}$, and $V_{E}$.

Class b.- In thirty-six cases there was no late $\mathrm{R}^{\prime}$ deflection in Lead $\mathrm{V}_{\mathbf{E}}$, but such a deflection was present in Leads $\mathrm{V}_{1}$ and $\mathrm{V}_{2}$.

Class c.- In five cases $R$ and $R^{\prime}$ waves were present in Leads $V_{1}$ and $V_{E}$, but there was no secondary $R^{\prime}$ wave in Lead $V_{2}$.

Class d.- In twenty-four cases $\mathrm{R}$ and $\mathrm{R}^{\prime}$ waves were conspicuous in Lead $\mathrm{V}_{1}$ only.

Class e.- In thirteen cases an initial and a secondary $R$ wave were present in Lead $V_{1}$ or in Leads $V_{1}$ and $V_{2}$, but Lead $V_{E}$ had not been taken. These cases were at first placed in this class. Later those cases in which $R$ and $R$ ' waves were present in Lead $V_{1}$ only were added to Class $d$ and those in which these deflections occurred in Lead $\mathrm{V}_{2}$ as well were added to Class b.

Table I. Classification of Incomplete Right Bundle Branch Block

\begin{tabular}{|c|c|c|c|c|c|c|c|}
\hline GROLP & $\mathrm{a}$ & b & c & d & TOTAL & $\begin{array}{c}\text { CORRECTED } \\
\text { TOTAL }\end{array}$ & $\begin{array}{l}\text { PROBABLE } \\
\text { CASES }\end{array}$ \\
\hline $\begin{array}{l}\text { I } \\
\text { II } \\
\text { III } \\
\text { IV, A } \\
\text { IV, B } \\
\text { IV, C } \\
\text { IV, I } \\
\text { V } \\
\text { VI } \\
\text { VII }\end{array}$ & $\begin{array}{r}14 \\
9 \\
3 \\
7 \\
2 \\
5 \\
2 \\
4 \\
1 \\
\end{array}$ & $\begin{array}{l}9 \\
7 \\
4 \\
3 \\
5 \\
1 \\
3 \\
4 \\
0 \\
\end{array}$ & $\begin{array}{l}1 \\
3 \\
0 \\
0 \\
0 \\
0 \\
0 \\
0 \\
1 \\
\end{array}$ & $\begin{array}{r}4 \\
3 \\
12 \\
1 \\
1 \\
0 \\
0 \\
3 \\
0 \\
\end{array}$ & $\begin{array}{r}28 \\
22 \\
19 \\
11 \\
8 \\
6 \\
5 \\
11 \\
2 \\
1\end{array}$ & $\begin{array}{r}27 \\
20 \\
11 \\
10 \\
7 \\
6 \\
5 \\
8 \\
2 \\
1\end{array}$ & $\begin{array}{l}1 \\
2 \\
8 \\
1 \\
1 \\
0 \\
0 \\
3 \\
0 \\
0\end{array}$ \\
\hline \multicolumn{5}{|c|}{ Tota l } & 113 & 97 & 16 \\
\hline
\end{tabular}

Table I shows the distribution with respect to classes of the cases placed in each of the groups or subgroups. The column headed "Total" gives the sum of the numbers which appear on the same horizontal line in the four preceding columns. The column headed "Corrected Total" gives the sum of the figures lying on the same horizontal line and in the columns headed "a," "b," and "c," plus a number representing cases placed in Class $d$, in which the evidence pointing to incomplete right bundle branch block exhibited by the standard precordial leads was supported by data furnished by unipolar leads from points to the right 
of the right sternal margin, or by other records depicting complete right bundle branch block in the same patient. The column headed "Probable Cases" gives the difference between the figure in the sixth column and that in the seventh.

There were nineteen cases in which the records taken disclosed a variation in the grade of the defect in conduction. In four instances both complete and incomplete right bundle branch block were recorded. In the remainder, which are not included in our series of cases of incomplete right bundle branch block, partial or transient complete right bundle branch block was observed.

\section{CASES SHOWING VARIATIONS IN THE GRADE OF THE CONDUCTION DEFECT}

The least questionable cases of incomplete right bundle branch block are those in which complexes typical of complete right bundle branch block and complexes transitional in form between these and complexes of normal outline occur either in the same record or in the same set of records. For this reason, we have selected two cases of this kind for discussion. In order to bring out more
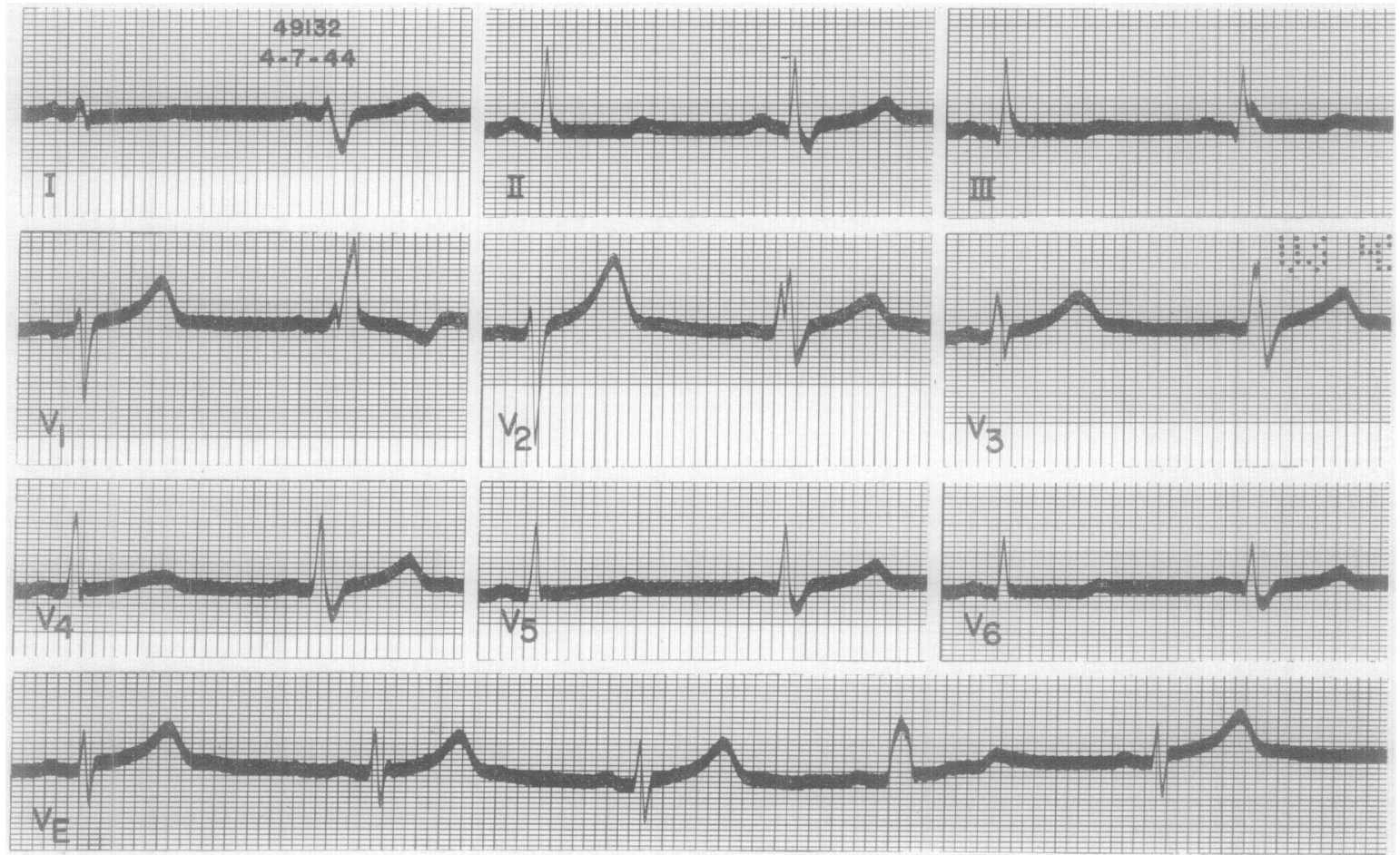

Fig. 1,-Partial right bundle branch block. The first complex of each pair represents normal intraventricular conduction; the second, complete right bundle branch block. (Reproduced with the permission of Interscience Publishers, Inc.) 
clearly the similaritics and differences between the two types of complexes, we have in some instances superimposed them photographically by the following procedure:

The film negative of the original electrocardiogram was printed as a positive on another strip of film. Both the negative and the positive were then put in a photographic enlarger, and a complex representing complete right bundle branch block was superimposed, in the proper time relation, upon one representing incomplete right bundle branch block, or, in one instance, normal intraventricular conduction. This was done by shifting the two complexes until the $\mathrm{P}$ waves and the earliest QRS components coincided, while keeping the two sets of time lines, the two sets of horizontal lines, and the two iscelectric levels parallel. The enlarged photograph made in this way shows a white and a black tracing, one upon the other, with white grid lines belonging to the first and black grid lines belonging to the second. Where black and white deflections or lines coincide the resulting tone is grav.

For purposes of comparison and orientation, we shall present first a case of partial right bundle branch block in which complexes typical of complete right bundle branch block and complexes of normal contour occurred in the same record.

The patient, a man 40 years of age, was found to have a defect in intraventricular conduction when an electrocardiogram was taken elsewhere, on Sept. 8, 1941, in the course of a routine examination. At a later date, May 24, 1943, another tracing showed normal intraventricular conduction; but on Dec. 17, 1943, right bundle branch block was again present. There were no complaints referable to the heart, and the physical examination was entirely negative. The electrocardiogram taken on April 7, 1944, at the Lniversity Hospital shows in all leads a succession of ventricular complexes ty pical of complete right bundle branch block, alternating with runs of complexes of normal outline. In Fig. 1 the first complex of each pair is normal and the second depicts the block. The QRS interval of the former measures 0.08 second and that of the latter, 0.12 second.

There is a striking similarity between the initial deflections of the two types of complexes in the limb leads and in precordial Leads $V_{1}, V_{4}, V_{5}$, and $V_{6}$. There is a vast difference, however, between the later QRS components, and this is most pronounced in the leads from the right side of the precordium. When right bundle branch block is present, there is in Lead $V_{1}$ a small primary $R$ wave followed by a small downward movement which does not cross the base line, and this in turn is succeeded by a very tall secondary $R$ wave. The normal QRS complex displays a small initial $R$ deflection and a deep $S$ deflection. Both types of complexes undergo the expected transformations in the successive leads of the precordial series.

The paired complexes of Lead $V_{1}$ are superimposed in Fig. 2. The white tracing represents complete right bundle branch block and the black one, normal 
conduction. The initial deflections of the two complexes are nearly identical in form. The tracings diverge at a point on the descending limb of the initial $R$ wave of the abnormal'complex.

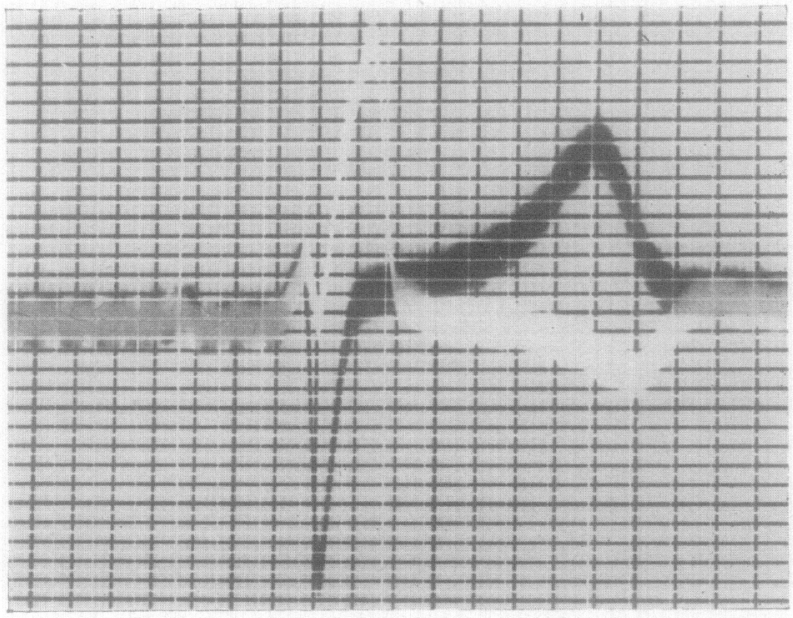

Fig. 2.-The paired complexes of Lead $v_{1}$ (Fig, 1) are superimposed.

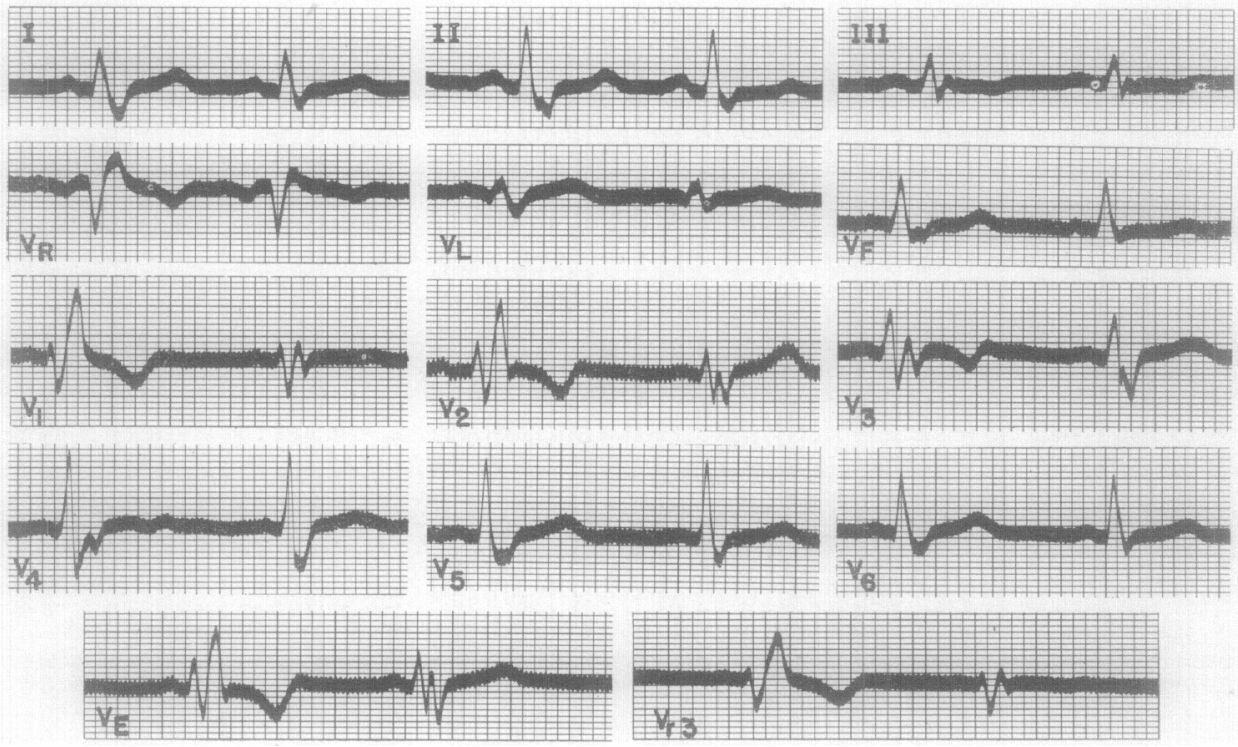

Fig. 3.-The first complex of each pair represents complete, the second incomplete right bundle branch block.

The electrocardiogram reproduced in Fig. 3 is that of a 65-year-old man who was admitted to the University I lospital on Feb. 5, 1941, for the repair of bilateral inguinal hernias. There was a history suggestive of nocturnal dyspnea, but no other complaints referable to the heart were elicited. On physical examination the cardiac border extended $10 \mathrm{~cm}$. to the left of the midline. There were no murmurs, but a presystolic gallop rhythm was heard. The blood pres- 
sure was $150 / 80$. Aside from moderate peripheral arteriosclerosis, there were no abnormalities of the cardiovascular system.

The electrocardiogram taken on Feb. 18, 1941, shows complete, alternating with incomplete, right bundle branch block. In Lead I, the first complex, which represents complete block, displays brcad W-shaped QRS complexes with a duration of 0.14 second. The QRS complex of the second complex measures only 0.10 second. The initial parts of the paired complexes appeared to be identical in all leads. In the limb leads and in the leads from the left side of the precordium ( $V_{5}$ and $V_{6}$ ), they difler chiefly with respect to the width of the QRS group and the size of the $\mathrm{T}$ deflection. In the leads from the right side of the precordium $\left(V_{1}, V_{2}\right.$, and $V_{E}$ ) and from the right fourth intercostal space in the midclavicular line $\left(V_{\mathrm{R}_{3}}\right)$, the difference between them is much more pronounced.

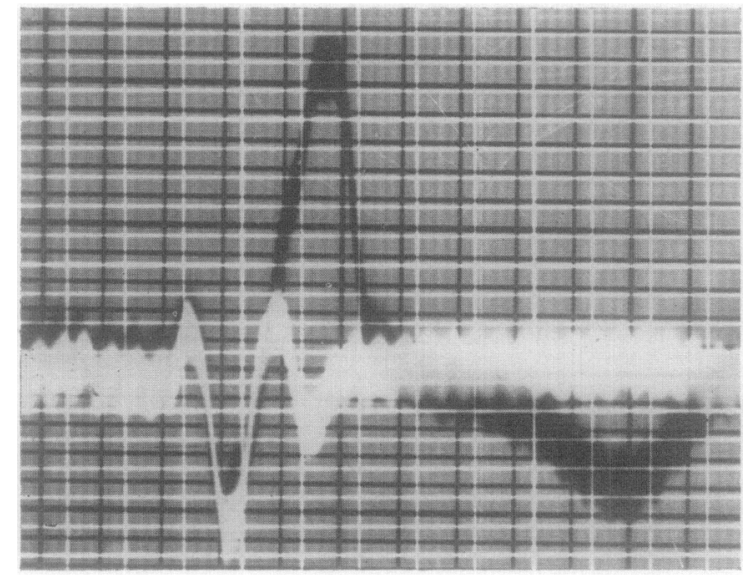

Fig. 4. - The paired complexes of Lead $v_{1}$ (Fig. 3) are superimposed.

Note that the $\mathrm{R}^{\prime}$ deflections are much taller in the complexes that represent complete, than in those that represent incomplete right bundle branch block. In Leads $V_{1}$ and $V_{R 3}$ the $R^{\prime}$ deflection of the latter is approximately equal to the $R$ wave in height; in Lead $V_{2}$ it is smaller than the $R$ wave; and in Lead $V_{F}$ it is embryonic. There is an orderly sequence of changes affecting the primary and secondary $R$ waves of both complexes corresponding to the step-by-step movement of the exploring electrode from the right to the left side of the precordium as the successive leads were taken. The primary $\mathrm{R}$ wave grows taller and finally becomes the early $R$ wave of the leads from the extreme left side of the precordium, whereas the second $\mathrm{R}$ deflection becomes gradually smaller and is eventually transformed into an $S$ wave.

It is evident that except for the height of the secondary $R$ deflection the QRS complexes of shorter duration closely resemble in general outline and behavior those which are characteristic of complete right bundle branch block. There can be little doubt that the former represent incomplete right bundle branch block. These complexes are typical of those recorded in the cases which we have placed in Group I, Class a (Fig. 7,A). In Fig. 4 the paired complexes 
of Lead $V_{1}$ are supcrimposed. It will be noted that the primary $R$ waves and the downstrokes of the $\mathrm{S}$ waves coincide. The divergence begins near the peak of the $R^{\prime}$ deflection of the complex of shorter duration.

The electrocardiograms reproduced in Figs. 5 and 6 are those of a 59-year-old man who was well until Aug. 23, 1945, when he had a prolonged attack of anginal pain followed by unconsciousness for two hours, and right hemiplegia which persisted for twenty-four hours. Dy spnea and palpitation continued through the following two weeks, at the end of which time the patient was admitted to the University Hospital. Examination revealed moderate cyanosis, a heart rate of 140 per minute with regular rhythm, a blood pressure of $128 / 80$, and a greatly enlarged heart. A Grade 1 blowing systolic murmur was audible in the pulmonic area.
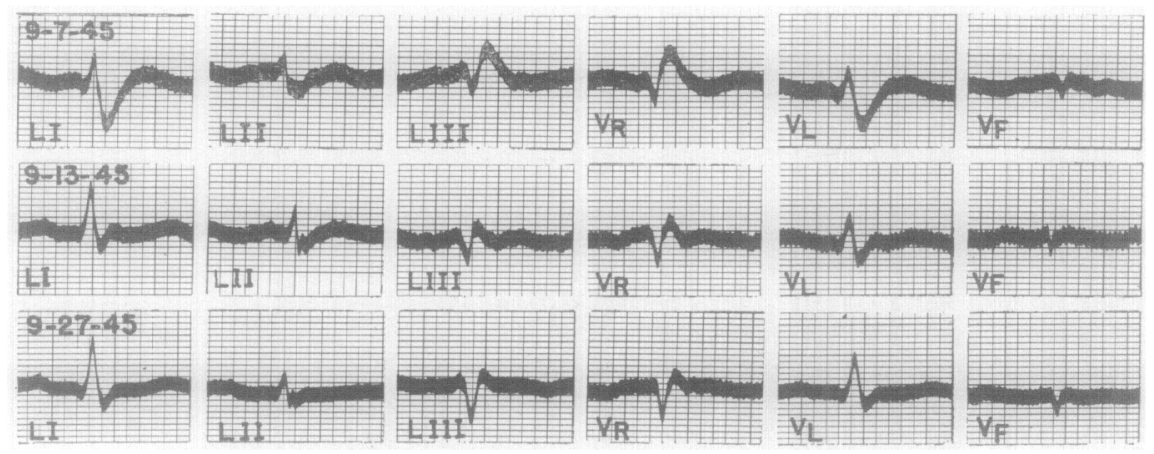

Fig. 5.-Different grades of right bundle branch block in the tracings of a 59-year-old man, who had a prolonged attack of anginal pain followed by transient hemiplegia, cardiac failure, and auricular flutter.

The electrocardiogram taken on Sept. 7, 1945, showed complete right bundle branch block. No distinct $P$ waves were visible in the standard limb leads, but small continuous oscillations, occurring at a rate of 272 per minute, in the leads from the right side of the precordium disclosed the presence of auricular flutter with 2:1 A-V block. In the precordial leads (Fig. 0) the transitional zone is shifted somewhat to the left; compare the complexes of Lead $V_{4}$ in this record with those of Lead $V_{1}$ in Fig. 8, in which the transitional zone is well to the right. Leads from the left side of the precordium $\left(V_{5}\right.$ and $\left.V_{6}\right)$ show early $R$ waves and broad S deffections.

The complexes of the records of Sept. 13, 1945, are similar in outline, but the QRS interval varies considerably in duration. The heart rate is 100 per minute and the grade of $\mathrm{A}-\mathrm{V}$ block is variable. The QRS complexes change in shape with the length of the preceding diastole. Thus, when the block is $2: 1$ the QRS interval measures 0.14 second, and when $4: 1$ block is present this interval measures 0.12 second. In the record taken on Sept. 27, 1945, there is normal sinus rhythm with a heart rate of 94 per minute, and the QRS interval measures 0.11 second. The only other evidence of a conduction defect in the precordial leads of this date is the presence of both an early and a late $R$ deflec- 
tion in Lead $V_{1}$. The significance of an $R^{\prime}$ deflection in Lead $V_{1}$ alone, in cases in which there is no other evidence of heart disease, is often open to question. Certainly, in the present instance, this phenomenon appears to represent the residuum of the previously complete right bundle branch block, and therefore a minor grade of incomplete right bundle branch block.

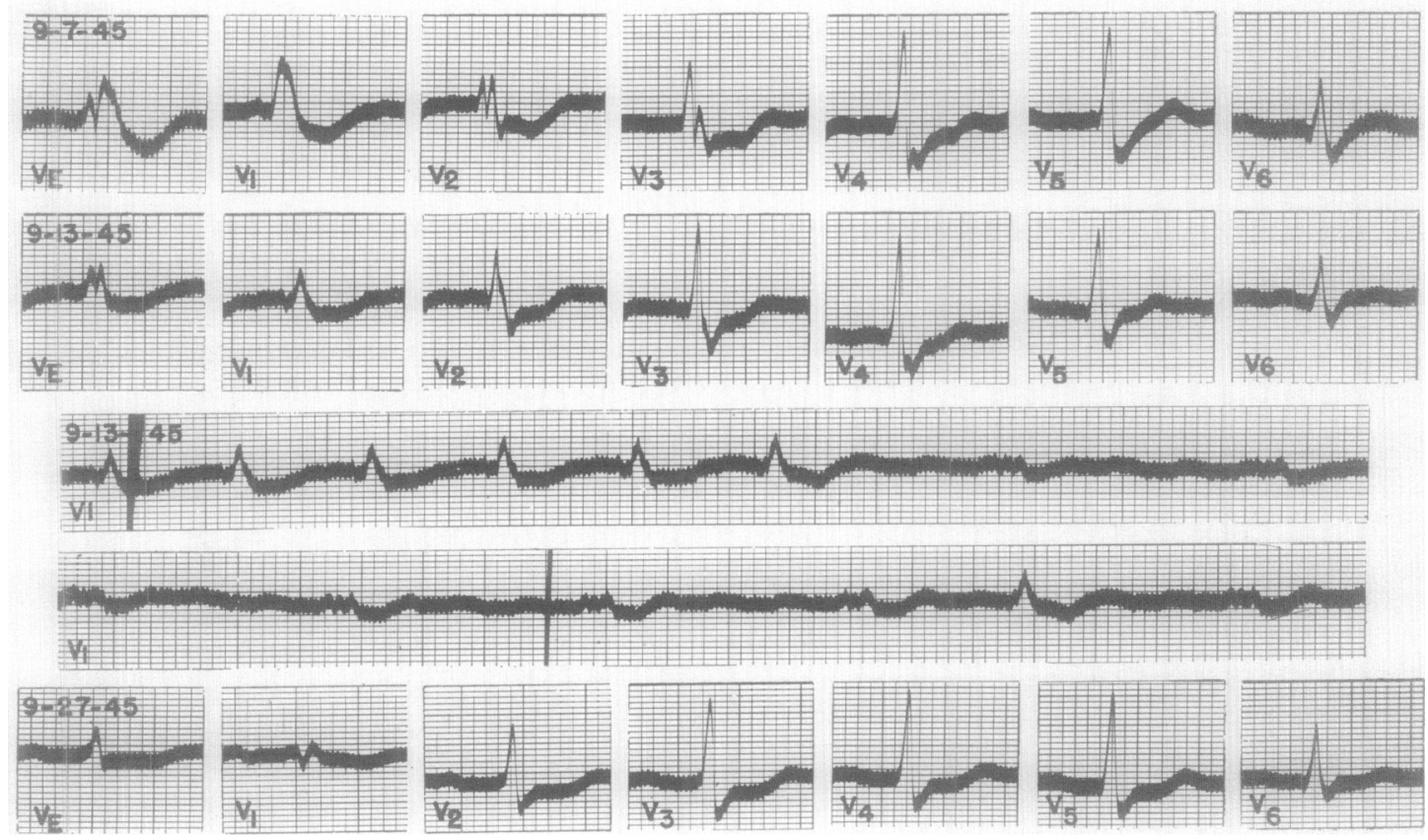

Fig. 6.-The precordial leads corresponding to the limb leads of Fig. 5,

DEFINITION OF INCOMPLETE RIGHT BUNDLE BRANCH BLOCK AND THE ORIGIN OF THE QRS DEFLECTIONS IN LEADS FROM THE RIGH'I SIDE OF THE PRECORDIUM

The concept of incomplete bundle branch block is based on an analogy. Between complete and permanent A-V block, on the one hand, and slight prolongation of the P-R interval, on the other, there are many conduction defects of intermediate grade. Similar variations in the effects of disease upon the spread of the excitatory process through the bundle branches, which have a structure not unlike that of the main stem of the bundle of His, are to be expected. Complete bundle branch block is now known to be fairly common, and partial bundle branch block, in which normal intraventricular conduction alternates with complete bundle branch block, is by no means rare. The term incomplete bundle branch block is used to designate a delay in the activation of one ventricle due to a defect which slows, but does not interrupt, the transmission of the impulse through the main stem of the bundle branch which supplies this chamber. This 
delay cannot exceed that which would be produced by complete block in the same case, but from a theoretical standpoint it may have any lesser magnitude. Practically, it must be great enough to be detectable by the methods available. The term incomplete bundle branch block as defined here excludes defects in conduction affecting the transmission of impulses through some subdivision of a bundle branch but not through the bundle branch as a whole.

Defects in conduction affecting the right branch of the bundle of His cannot alter the time or sequence of the excitation of the muscle normally supplied by the left branch. The electrical forces produced by the activation of this fraction of the myocardium are, therefore, in all respects the same when such defects are present as when they are absent. When there is a delay in the activation of the right ventricle, as much of the QRS complex as is written before excitation of this chamber begins is pure levocardiogram. The earliest part of the QRS complex has the same form in incomplete as in complete right bundle branch block; in both cases, it is of left ventricular origin. Theoretically, it should, then, always be possible when QRS complexes typical of complete right bundle branch block and QRS complexes of shorter duration occur in the same tracing, or same set of tracings, to ascertain whether the latter do, or do not, represent incomplete right bundle branch block, by comparing the initial components of the two types of complexes. In practice the comparison does not always give an entirely unequivocal answer, particularly when it is a question of deciding whether or not the less abnormal complexes depict a minor delay in the activation of all of the right ventricular muscle. The reason lies chiefly, although not solely, in the similarity between the initial QRS component of the complexes which represent complete right bundle branch block and that of those which represent normal intraventricular conduction in the same subject. This similarity is well illustrated by Figs. 1 and 2 .

When the excitatory impulse reaches the ventricles by way of the bundle of $\mathrm{His}$ and its subdivisions, its direction of spread through each part of the ventricular walls and septum is perpendicular, or nearly perpendicular, to the endocardial surface which bounds it. Four sets of electrical surfaces are generated. Two of these, the forces produced by activation of the right half of the septum and those produced by activation of the free wall of the left ventricle, tend to make the epicardial surface of this chamber and the left side of the thorax positive, and the epicardial surface of the right ventricle and the right side of the thorax negative. The other two, the septal forces of the left ventricle and those produced by the free wall of the right, have the opposite polarity. The forces produced by the right side of the septum tend to make the cavity of the left ventricle positive and that of the right negative, and vice versa. The forces produced by the free walls tend to make both cavities negative. It is clear, therefore, that the QRS deflections always represent a balance of forces directly opposed one to the other.

It has been shown that the potential variations of any point on the precordium are closely related to those of the nearest parts of the epicardial surface. ${ }^{3}$ The deflections of unipolar leads from the right side of the precordium are ordinarily similar in general outline and in origin to the deflections of unipolar 
direct leads from the anterior surface of the right ventricle. One method of analyzing the QRS deflections of direct leads of this kind is to regard them as depicting the electrical forces produced by the part of the ventricular wall in contact with the exploring electrode, measured from a fluctuating base line which represents the potential variations of the adjacent ventricular cavity. In a similar way we may regard the potential variations of the cavity of the right ventricle which occur during a period when its septal wall, but not its free wall, is undergoing activation, as changes in potential produced by the septal muscle plotted upon the time-course of the potential of the left ventricular cavity as reference level. In right bundle branch block the cavity of the left ventricle is negative throughout the QRS interval while that of the right ventricle is initially positive. It is clear that this initial positivity is due to activation of the septum from left to right. Since it occurs before activation of the free wall of the right ventricle has begun, it is transmitted to the epicardial surface of this wall and to the right side of the precordium. An initial $R$ wave in the leads from the right side of the precordium in complete and incomplete right bundle branch block is therefore ascribed to forces produced by the spread of the impulse through the septum from left to right.

When the initial component of QRS has almost exactly the same form when intraventricular conduction appears to be normal as when complete right bundle branch block is present, as in the case illustrated by Figs. 1 and 2, it is difficult to avoid the conclusion that it represents the same phenomenon in both cases. It was shown long ago that in dogs, leads from the cavity of the right ventricle often display a small initial $\mathrm{R}$ deflection indicating that the left side of the septum is activated before the right side. Recently, leads from the cavity of the human right ventricle have demonstrated that this is regularly the case in man." It is highly probable, therefore, that the resemblance in question is not peculiar to cases of partial right bundle branch block, and that in most, if not all, normal electrocardiograms the initial $\mathrm{R}$ wave in Lead $V_{1}$ is mainly of septal origin. It can, however, hardly be due to septal forces alone, for this lead displays a small initial $R$ wave in the majority of the cases of left bundle branch block in which this deflection must represent forces produced by activation of the free wall of the right ventricle. When intraventricular conduction is normal, or nearly: so, there is no way of estimating in a given instance how much of the initial $R$ wave of Lead $V_{1}$, or some other lead from the right side of the precordium, is contributed by forces arising in this wall and how much by forces generated in the septum. The early and rapid development of strong forces, opposed to both of these, in the free wall of the left ventricle makes it hard to ascertain the time-course of those produced by that of the right. These opposing left ventricular forces make the initial $R$ wave of the leads from the right side of the precordium much smaller than it would otherwise be both in right bundle branch block, complete or incomplete, and when no conduction defect is present: It is probable that they are mainly responsible for the distinct separation of the $\mathrm{R}$ and $\mathrm{R}^{\prime}$ deflections of the former. It is noteworthy that no similar separation occurs in the leads from the left side of the precordium in left bundle branch block and that in right bundle branch block the early large $R$ wave of these leads is 
simultaneous or nearly simultaneous with the cleft between the $R$ and $R^{\prime}$ waves in the leads from the right side.

In right bundle branch block two of the four sets of forces generated by excitation of the ventricular myocardium are altered with respect to the time of their occurrence, to their polarity, or to both. The forces produced by all or part of the right half of the septum are generated abnormally late in the QRS interval and their polarity is reversed, so that they tend to make both the cavity of the right ventricle and the epicardial surface of this chamber positive instead of negative. The forces produced by the free wall of the right ventricle are delayed still more, but their polarity is not affected. In incomplete right bundle branch block there is no reason to suppose that their magnitude is abnormal or that the order in which the various parts of the free wall of the right ventricle become active is modified. In complete right bundle branch block, however, the contrary is probably the case, for the excitatory impulse reaches the right ventricle by an abnormal route and presumably spreads over the right ventricular muscle in an abnormal fashion. It seems likely that the general course of the impulse from right to left over this muscle gives rise to some electrical forces which are tangential to the inner and outer boundaries of the parts of the wall in which they are generated. ${ }^{6}$ Such forces would tend to make the right side of the precordium more positive than it would be if the order of activation of the different fractions of the free wall of the right ventricle were normal.

It is clear that when the $\mathrm{R}^{\prime}$ deflection is the terminal component of the QRS complex of the leads from the right side of the precordium, the latest part of it must be ascribed to forces produced by late activation of some part of the free wall of the right ventricle. The origin of the earlier fractions of this deflection can only be ascertained with certainity by comparing them with the simultaneous deflections of leads from the cavity of the right ventricle. In canine right bundle branch block, such leads usually display a tiny preliminary upward deflection followed by a moderately tall $\mathrm{R}$ wave which is succeeded by an $\mathrm{S}$ wave of approximately equal voltage. In epicardial and precordial leads the preliminary deflection is clearly visible, but the main septal $R$ wave is fused with the upward deflection produced by activation of the free wall of the right ventricle to form a broad $R^{\prime}$ wave, which usually displays on its ascending limb a notch marking the junction of its two components. ${ }^{7}$ We must assume, then, that in human right bundle branch block the earliest part of the $\mathrm{R}^{\prime}$ deflection of the leads from the right side of the precordium is sometimes, if not always, due in part to forces of septal origin.

Consider now the differences between complete and incomplete right bundle branch block and between the different grades of incomplete right bundle branch block with regard to the times of occurrence and magnitudes of the two sets of forces tending to make the right side of the precordium positive during the latter part of the QRS interval. Any abnormal septal forces, due to activation of some part of the right half of the septum from left to right instead of in the opposite direction, which may be present must begin at the same time with respect to the onset of the first QRS deflection, regardless of the grade of the conduction 
defect. On the other hand, the magnitude and duration, perhaps only the duration, of these forces must be proportional to the delay in the activation of the right ventricle. The magnitude of the forces produced by the free wall of this chamber may be considerably smaller in incomplete than in complete right bundle branch block, but in all grades of the former it must be the same. The time of occurrence of these forces in the QRS interval, unlike that of the septal forces, measures exactly the grade of the conduction defect. The area of the QRS deflections in any given lead is determined by the direction in which the various parts of the ventricular myocardium are activated and not by the times of their activation. ${ }^{8}$ In right bundle branch block, the change in the area of QRS due to the reversal of the direction in which a part or all of the right half of the septum is activated should be twice as large as the change in area that would be produced by the replacement of this part of the septum by scar tissue. On the other hand, if we disregard the tangential forces mentioned in a previnus paragraph, the area contributed to QRS by activation of the free wall of the right ventricle should be the same in all grades of right bundle branch block.

It is not difficult to understand why the $\mathrm{R}^{\prime}$ deflection of the leads from the right side of the precordium is so much smaller in incomplete than in complete right bundle branch block. If the first part of this deflection is of septal origin, we can also understand why its upstroke may begin at the same time in the QRS interval in both cases. In Leads $V_{1}$ and $V_{r 3}$ of Fig. 3, the $R^{\prime}$ deflection of the second of the paired complexes begins at the same time and at the same level as that of the first. In Leads $V_{2}, V_{3}, V_{4}$, and $V_{\mathrm{E}}$ it begins at a slightly higher level and perhaps a trifle earlier in the QRS interval. In all of the leads from the right side of the precordium, the reduction in the grade of the block caused a shift of the apex of the $\mathrm{R}^{\prime}$ wave toward the beginning of the QRS interval greater than the decrease in the length of this interval which it produced (Fig. 4). In Fig. 6 the decrease in the size of the $\mathrm{R}^{\prime}$ deflection in Leads $V_{1}$ and $V_{E}$ as the grade of the block diminished is very striking; in the latter lead this deflection disappeared altogether. The initial $\mathrm{R}$ deflection did not change. In Leads $V_{2}$ and $V_{3}$ the second $R$ wave of the first record shifted toward the beginning of the QRS interval as the grade of the block diminished, for in the later records this deflection is clearly superimposed upon the initial $R$ wave, which has become much taller. Its behavior suggests that it represents forces generated by the free wall of the right ventricle rather than by the septum. It is obvious that the relative magnitude of the septal and free-wall components of the $R^{\prime}$ deflection may vary greatly from lead to lead. This is in no way surprising.

\section{INCOMPLETE RIGHT BUNDLE BRANCH BLOCK VERSUS LOCAL BLOCK}

The question arises as to whether it is possible to distinguish with certainty, by means of precordial leads, between incomplete right bundle branch block, as we have defined it, and a defect in conduction located in one of the subdivisions of the right branch of the bundle of His or in the right Purkinje plexus. In the former the intrinsic deflection would be equally delayed in unipolar leads from every part of the right ventricular surface; in the latter this 
deflection would be abnormally late only in the leads from that part of the ventricular wall supplied by the subdivision or the part of the plexus, affected. In incomplete right bundle branch block evidence of a delay in the activation of the surface of the right ventricle would, therefore, be expected to appear in all unipolar precordial leads in which the exploring electrode is placed much closer to this surface than to that of the left ventricle. In block affecting a subdivision of the right bundle branch, on the other hand, one would expect to find such evidence in some of these leads, but not in others. It is for this reason that we have classified our cases with respect to the number of leads from the right side of the precordium showing a secondary $\mathrm{R}$ wave. We felt, for example, that the evidence pointing to the presence of incomplete right bundle branch block was much stronger when there was a conspicuous $\mathrm{R}^{\prime}$ deflection in both Lead $V_{1}$ and Lead $V_{F}$, which are from points relatively far apart and presumably reflect the potential variations of quite different parts of the right ventricular surface, than when such a deflection was present in Lead $\mathrm{V}_{1}$ only. Consequently, the class to which a given electrocardiogram was assigned indicates, in some measure, our opinion as to the probability that it represents incomplete right bundle branch block. When the $\mathrm{R}^{\prime}$ deflection is present in only one precordial lead, the possibility that it is the result of local block, or has some other origin, must be seriously considered. We do not, however, by any means believe that incomplete right bundle branch block can be excluded under these circumstances. It will be noted that in both Fig. 3 and Fig. 6, the number of leads which display an $\mathrm{R}^{\prime}$ deflection is larger when the prolongation of the QRS interval is greater. It seems much more likely that each of these figures represents variations in the grade of a single conduction defect, than that each of them represents two or more distinct conduction defects. The latter possibility cannot, perhaps, be excluded with finality.

It should be pointed out in this connection that although unipolar precordial leads resemble unipolar direct leads in many ways, they differ from them in one important respect. The latter record the potential variations of a single point on the epicardial surface, whereas the former depict a mixture of the potential variations of all parts of the ventricular surfaces in which the potential changes of the nearest parts of this surface are ordinarily the dominant components. It is not necessarily true that the precordial area which yields evidence of delayed activation of the right ventricle when there is a minor delay in the transmission of the impulse through the right branch of the bundle of His will coincide exactly with the precordial area that vields similar evidence when complete right bundle

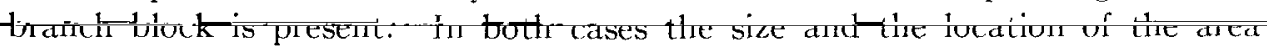
in question are affected by many factors, such as the distance of the anterior wall of the heart from the surface of the precordium, the position of the heart as a whole, and rotation of the heart about its long axis.

THE QRS INTERVAL,

In hearts of normal size the free wall of the left ventricle is approximately three times as thick as that of the free wall of the right. If the excitatory impulse spreads through both walls with the same speed, activation of the left 
ventricular wall should take much longer than that of the right. The duration of QRS is normally determined, then, by the length of time it takes the excitation process to pass from the endocardial to the epicardial surface of the thickest part of the free wall of the left ventricle. Theoretically, therefore, it is possible in incomplete right bundle branch block of minor degree to have a QRS interval of normal length. In slightly less than one-half of our cases, the QRS interval was less than 0.10 second (Table II), while in the others it was between 0.10 and 0.12 second.

TABLE II. ThE QRS INTERVAL

\begin{tabular}{|c|c|c|c|c|c|c|}
\hline \multirow{2}{*}{ GROUP NO. } & \multirow[b]{2}{*}{$\begin{array}{l}\text { LONGEST } \\
\text { (SECOND) }\end{array}$} & \multirow[b]{2}{*}{$\begin{array}{l}\text { SHORTEST } \\
\text { (SECOND) }\end{array}$} & \multirow[b]{2}{*}{$\begin{array}{l}\text { AVERAGE } \\
\text { (SECOND) }\end{array}$} & \multicolumn{3}{|c|}{ NUMBER OF CASES } \\
\hline & & & & $\begin{array}{l}0.10 \text { SECOND } \\
\text { OR MORE }\end{array}$ & $\begin{array}{l}\text { LESS THAN } \\
0.10 \text { SECOND }\end{array}$ & TOTAL \\
\hline $\begin{array}{l}\text { I } \\
\text { II } \\
\text { III } \\
\text { IV, A } \\
\text { IV, B } \\
\text { IV, C } \\
\text { IV, D } \\
\text { V } \\
\text { VI } \\
\text { VII }\end{array}$ & $\begin{array}{l}0.115 \\
0.115 \\
0.11 \\
0.115 \\
0.11 \\
0.10 \\
0.11 \\
0.11 \\
0.10 \\
0.08\end{array}$ & $\begin{array}{l}0.08 \\
0.08 \\
0.08 \\
0.08 \\
0.07^{*} \\
0.09 \\
0.09 \\
0.09 \\
0.09 \\
0.08\end{array}$ & $\begin{array}{l}0.099 \\
0.097 \\
0.91 \\
0.105 \\
0.087 \\
0.091 \\
0.10 \\
0.099 \\
0.095 \\
0.08\end{array}$ & $\begin{array}{r}17 \\
11 \\
8 \\
7 \\
2 \\
2 \\
3 \\
5 \\
1 \\
0\end{array}$ & $\begin{array}{r}10 \\
9 \\
3 \\
3 \\
5 \\
4 \\
2 \\
3 \\
1 \\
1\end{array}$ & $\begin{array}{l}27 \\
20 \\
11 \\
10 \\
7 \\
6 \\
5 \\
8 \\
2 \\
1\end{array}$ \\
\hline VII & & & & 55 & 41 & 97 \\
\hline
\end{tabular}

*In a child six years old.

At times it is difficult to know with certainty whether an electrocardiogram which displays a QRS interval measuring between 0.10 and 0.12 second represents incomplete or complete right bundle branch block, particularly when the deflections of the leads from the right side of the precordium have a configuration which closely resembles that produced by the latter. Since the QRS duration of some normal electrocardiograms does not exceed 0.06 or 0.07 second, it is quite possible that complete right bundle branch block may sometimes be present when the QRS interval is less than 0.12 second. Clearly, no hard and fast line can be drawn between high grade incomplete right bundle branch blcck, on the one hand, and complete right bundle branch block, on the other.

\section{CONFIGURATION OF THE COMPLEXES OF THE PRECORDIAL LEADS}

The various electrocardiographic patterns considered diagnostic or strongly suggestive of incomplete right bundle branch block are illustrated in Fig. 7 . The curves of this figure are arranged from above downward in the order of the groups in which they fall on the basis of the criteria given in an earlier section of this article.

The uppermost row of tracings $(A)$ are the precordial leads of a woman with extensive scleroderma. A previous electrocardiogram, taken on May 24, 
1944, was considered to be within normal limits. The tracing reproduced, which was taken on March 29, 1946, shows broad S waves in Lead I, which were not present in the earlier record. The QRS interval is the same in both tracings and measures 0.09 second in the limb leads. There are primary and secondary $\mathrm{R}$

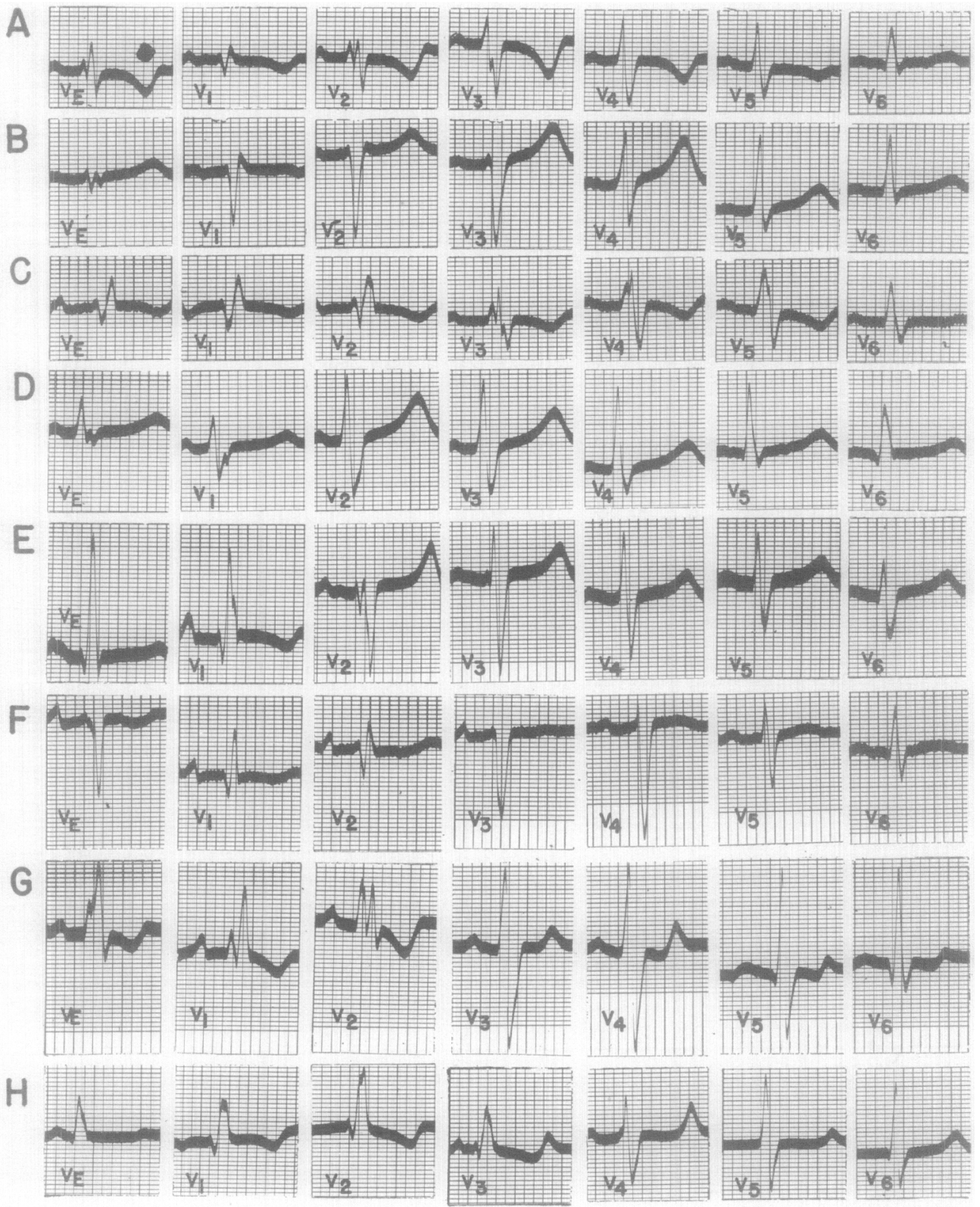

Fig. 7.-Various types of incomplete right bundle branch block $(A, B, C, D)$ and of incomplete right bundle branch block associated with right ventricular enlargement $(E, F, G, H)$. 
deflections, approxinately equal in size, and an $\mathrm{S}$ wave, a little over $2 \mathrm{~mm}$. in depth, in Lead $V_{1}$. In Lead $V_{2}$, the $Q R S$ complex consists of two small $R$ waves followed by a prominent $S$ wave. This lead is from the edge of the transitional zone. The complexes of the leads from the left side of the precordium $\left(V_{5}\right.$ and $V_{6}$ ) are essentially normal in general outline. The deflections of Lead $V_{r}$ are somewhat like those of Lead $\mathrm{V}_{2}$. This tracing belongs, therefore, to Group I, Class a.

The precordial electrocardiogram in the second row $(B)$ of Fig. 7 is that of a man 38 years of age whose extremity leads suggested the possibility of incomplete right bundle branch block. This was the reason for taking chest leads. There were no clinical findings referable to the heart; the cardiac examination was part of a routine physical checkup. In the tracing of Oct. 29, 1942, Lead $V_{1}$ shows small $\mathrm{R}$ and $\mathrm{R}^{\prime}$ waves separated by a deep $\mathrm{S}$ deflection. In the leads from the left side of the precordium there are tall $\mathrm{R}$ waves followed by rather broad $S$ waves. Leads $V_{3}$ and $V_{4}$ show $Q R S$ complexes which are transitional in form. The transitional zone is, therefore, in the usual position. This tracing was placed in Group II. Since there are signs of the conduction defect in the first 1 wo precordial leads and in Lead $V_{\mathrm{E}}$, it belongs to Class a.

The third set of curves ( $C$ of Fig. 7), taken on May 27, 1943, are those of a 72 -year-old man with coronary atherosclerosis. There is a prominent $S$ wave in Lead I, and the QRS interval in the limb leads measures 0.11 second. The leads from the right side of the precordium, including Lead $V_{\mathrm{E}}$, show a small initial $\mathrm{R}$ deflection followed by a rather deep $\mathrm{S}$ wave and a final $\mathrm{R}^{\prime}$ deflection which is comparatively tall. The leads from the left side of the precordium show rather tall $\mathrm{R}$ waves followed by broad $\mathrm{S}$ waves. This is an example of the curves placed in Group II, B. An electrocardiogram (not reproduced here) taken on Aug. 4, 1943, on this man is strongly suggestive of complete left bundle branch block, although the usual series of precordial leads did not cross the transitional zone. There were evidently bilateral bundle branch lesions in this patient, leading first to incomplete right bundle branch block and later to complete interruption of conduction on the left side.

The fourth tracing ( $D$ of Fig. 7 ) is a sample of the precordial records placed in Group III, Class c. The patient was a 48-year-old man with functional hy poglycemia. There were no demonstrable abnormalities on physical examination. The blood pressure was $120 / 70$. Leads $V_{1}$ and $V_{\mathrm{I}}$ of the tracing taken on Oct. 29, 1942, show a relatively tall primary $\mathrm{R}$ deflection followed by an $\mathrm{S}$ wave, in the trough of which there is a small embryonic $R^{\prime}$ deflection. As far as the $R^{\prime}$ deflection is concerned, these complexes resemble those often seen in leads from points farther to the left: compare Leads $V_{3}$ and $V_{4}$ of Fig. 1 with Lead $V_{I}$ of the present case. They are transitional in form between the complexes we have described as occurring in the leads from the right side of the precordium in the curves of Groups I and II and those which are found in the leads from the left side of the precordium. Eleven patients of this group show embryonic $R^{\prime}$ waves in the leads from the right side of the precordium. This characteristic indicates that the transitional zone is shifted far to the right, probably because of rotation of the heart in a clockwise direction about an axis pointing from 
the apex toward the base. In three of the patients belonging to Group III, additional leads were taken from the right side of the chest $\left(V_{r_{3}}\right.$ and $\left.V_{r_{4}}\right)$. These show typical M-shaped QRS complexes of the type usually seen in Lead $V_{1}$ in cases of Group I and Group II (Fig. 8).
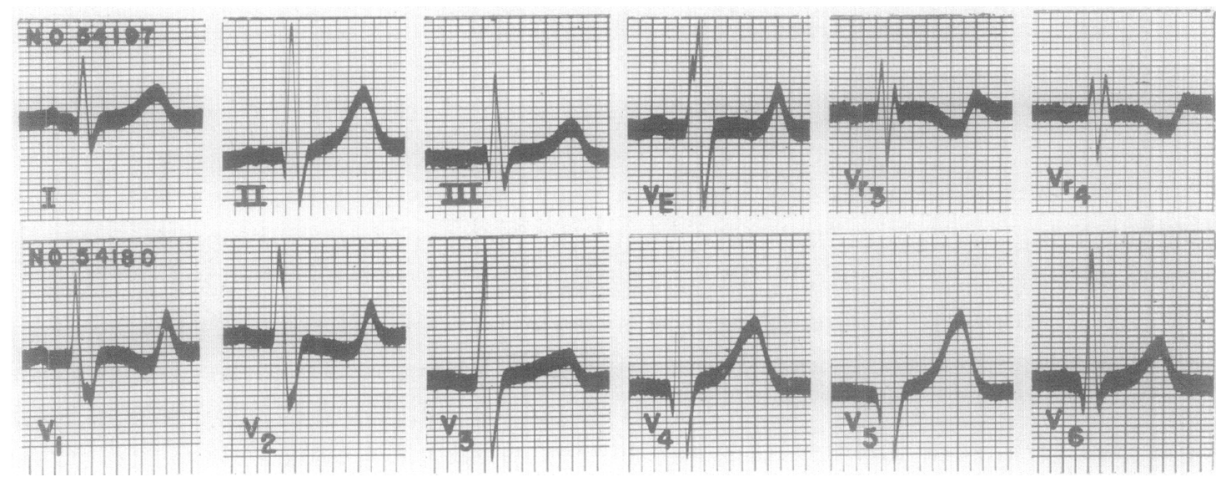

Fig. 8.- Incomplete right bundle branch block with displacement of the transitional zone to the right. Congenital anomaly of the heart (interventricular septal defect) in a girl $3 \frac{1}{2}$ years old.

The last four precordial electrocardiograms ( $E, F, G$, and $H$ of Fig. 7 ) are examples of the types found in incomplete right bundle branch block complicated by right ventricular hypertrophy, and are described in a later section.

THE TRANSITIONAL ZONE AND THE VAIUE OF ADDITIONAI. LEADS FROM THE RIGHT SIDE OF THE CHEST

As we have indicated in the section on classification, the class in which a given electrocardiogram was placed is an index of our opinion as to the probability that it represents incomplete right bundle branch block. It has been pointed out that in incomplete right bundle branch block one would expect to find evidence of late activation of the right ventricle in all of the leads from the right side of the precordium. A localized conduction defect involving the Purkinje network in a limited area, on the other hand, would be expected to affect only those leads in which the exploring electrode was placed directly over the region where activation was delayed. When the expected changes occur in Lead $V_{1}$ only (Class d) or are confined to Leads $V_{1}$ and $V_{2}$ (Class b), the diagnosis of incomplete right bundle branch block is made with some hesitation. If, however, there is a late $R^{\prime}$ deflection in both Lead $V_{1}$ and Lead $V_{E}$, which are from points far apart and must reflect the potential variations of quite different parts of the right ventricular surface, the diagnosis is made with greater confidence.

The main difference between the cases placed in Group III and those of the two preceding groups is that the transitional zone is farther to the right in those placed in Group III, so that the characteristic $R$ and $R^{\prime}$ waves are not found in the leads from the right side of the precordium. This observation led us to take additional leads from the right side of the chest $\left(V_{r_{3}}, V_{r_{4}}\right.$, etc.), and in every case in which they were used, they displayed double $R$ waves of the kind usually 
found in Leads $V_{1}, V_{2}$, and $V_{E}$. Data with respect to the kinds of cases in which such leads were taken are given in Table II. The value of these leads in substantiating the diagnosis of incomplete right bundle branch block is considerable, and it is recommended that they be employed whenever the limb leads and the leads from the right side of the precordium are suggestive, but not diagnostic, of this conduction defect. It must be remembered, however, that the farther the exploring electrode from the surface of the heart, the less accurately does the lead portray the potential variations of the nearest parts of the ventricular surface, and the more difficult is the interpretation of the ventricular deflections. It is conceivable that the leads under consideration may, under some circumstances, lead to an erroneous diagnosis of incomplete right bundle branch block.

There were five cases in Class $d$ and two in Class b in which additional leads from the right side of the chest were taken (Table III). All these showed evidence of late activation of the right ventricle. We have, therefore, considered these cases examples of incomplete right bundle branch block. In the tables there are columns headed "Certain" and others headed "Probable." Inder the former heading we have placed the cases of all classes except Class $d$, plus cases of alternating complete and incomplete right bundle branch block. There may be some question as to the correct diagnosis in the cases of Class $b$ in which no additional leads from the right side of the chest were taken. Because these cases resembled closely those in which such leads supported the diagnosis of incomplete right bundle branch block, and for the purpose of simplifying our classification and discussion, we have placed these cases with those which display more reliable evidence of the presence of this conduction defect.

Table III. Cases in Which the Clinical Diagnosis Was Confirmed or Established by Additional LEads to the Right, Correlated With the Groups and Subgroups Into Which They Were Classifjed

\begin{tabular}{c|c|c|c|c|c}
\hline GRoup & $\mathrm{a}$ & $\mathrm{b}$ & $\mathrm{c}$ & $\mathrm{d}$ & TOTAL \\
\hline II & 3 & 1 & 0 & 1 & 5 \\
II & 1 & 0 & 0 & 1 & 2 \\
III & 0 & 1 & 0 & 4 & 2 \\
IV, A & 2 & 0 & 0 & 0 & 1 \\
V & 1 & 0 & 0 & 2 \\
VII & 2 & 0 & 0 & 0 & 1 \\
\hline Tutal & - & - & - & 6 & 17 \\
\hline
\end{tabular}

The electrocardiogram reproduced in Fig. 8 is that of a girl $3 \frac{1}{2}$ years old. She was studied in the Pediatrics Outpatient Department of the University Hospital in August, 1945, because of anorexia, sleeplessness, and listlessness following an episode of otitis media one month earlier. She was not cyanotic at birth, but a few days later a diagnosis of congenital heart disease was made. Growth and development were about normal. Examination of the heart revealed a diffuse apical impulse. A faint systolic murmur was heard over the 
entire precordium, but was loudest in the third and fourth intercostal spaces to the left of the sternum. These findings were considered suggestive of an intraventricular septal defect. The electrocardiogram of Sept. 10, 1945, shows prominent $R$ waves and conspicuous $S$ waves in the three standard limb leads. The QRS interval measures 0.08 second. Lead $V_{1}$ displays a rather tall $R$ wave followed by an $S$ wave, in the trough of which there is an embryonic $R^{\prime}$ wave. Leads $V_{1}, V_{2}$, and $V_{3}$ exhibit QRS complexes similar to the kind usually found in Leads $V_{3}$ and $V_{4}$. They are transitional between those normally found in the leads from the right side of the precordium and the type normally found in the leads from the left side. The transitional zone is, therefore, far to the right. It was not crossed by the standard precordial leads. The leads from the left side of the precordium show a tall $R$ wave preceded by a $Q$ wave and followed by an $\mathrm{S}$ deflection. The potential variations of the tip of the ensiform process $\left(V_{E}\right)$ are also of transitional form, and the $R$ peak displays a prominent notch. In order to obtain curves from points to the right of the transitional zone, Leads $V_{r 3}$ and $V_{r 4}$ were taken. These show double $R$ waves of the kind we have described as indicative of incomplete right bundle branch block. Note the similarity, apart from the duration of the QRS interval, between the complexes of Lead $V_{1}$ in the present case and those of Lead $V_{4}$ in Fig. 6 (top row), which is one of a series of precordial leads that is characteristic of right bundle branch block, with the transitional zone a little to the left of the usual position. The potential variations of the left leg $\left(V_{F}\right)$ resemble those of the left precordium $\left(V_{5}\right.$ and $\left.V_{6}\right)$, while the potential variations of the left $\operatorname{arm}\left(V_{L}\right)$ are small. The heart was, therefore, in the semivertical position.

An even more striking example of the influence of the position of the transitional zone upon the configuration of the precordial electrocardiogram in incomplete right bundle branch block is shown in Fig. 9. The patient was a 17-year-old boy who was studied in the Outpatient Department of the University Hospital on April 13 and 14, 1944. He was not blue at birth. When he was one year old his parents noticed that the pulsations of his heart were unusually conspicuous, but the physician who was consulted reassured them. In 1935 the boy was told that he had heart trouble and that he should limit his activity. to some extent. Two years previous to the examination at this hospital he had rheumatic fever and was in bed for two months. During this time he had conspicuous cyanosis of the lips and nail beds. Examination of the heart revealed an intense thrill in the pulmonic area and along the left border of the sternum. In the same region there was a Grade $V$ rasping systolic murmur which was transmitted to the left. The heart was not enlarged. There was no cyanosis or acral clubbing. Although there was some uncertainty as to the proper diagnosis, the lesion was thought to be an auricular septal defect or pulmonic stenosis.

The electrocardiogram of April 14, 1944, shows broad S waves in all three standard limb leads. There is a relatively large $Q$ deflection in Lead $I$. The QRS interval measures 0.09 second. There is a prominent late $R$ wave in Lead $V_{R}$. Leads $V_{1}$ to $V_{6}$ all display $Q R S$ complexes of transitional form. Leads $V_{1}$ and $V_{E}$ show a slur on the upstroke of the $R$ wave. Lead $V_{7}$ exhibits small complexes with broad $S$ waves; in Lead $V_{8}$ the deflections are still smaller, but 
of the same general outline. In Lead $D_{\text {viii }}$ there are very small primary and secondary $\mathrm{R}$ deflections separated by a deep $\mathrm{S}$ deflection. The transitional zone

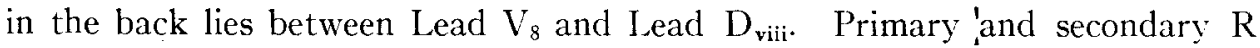
deflections are present in Leads $\mathrm{V}_{\mathrm{r} 8}, \mathrm{~V}_{\mathrm{r} 7}, \mathrm{~V}_{\mathrm{r} 6}$, and $\mathrm{V}_{\mathrm{r} 5}$, and the configuration of the QRS complex in these leads suggests delayed activation of the right ventricle. There is fusion of the two $R$ waves in Lead $V_{r 5}$. Iead $V_{r_{4}}$ is near the border

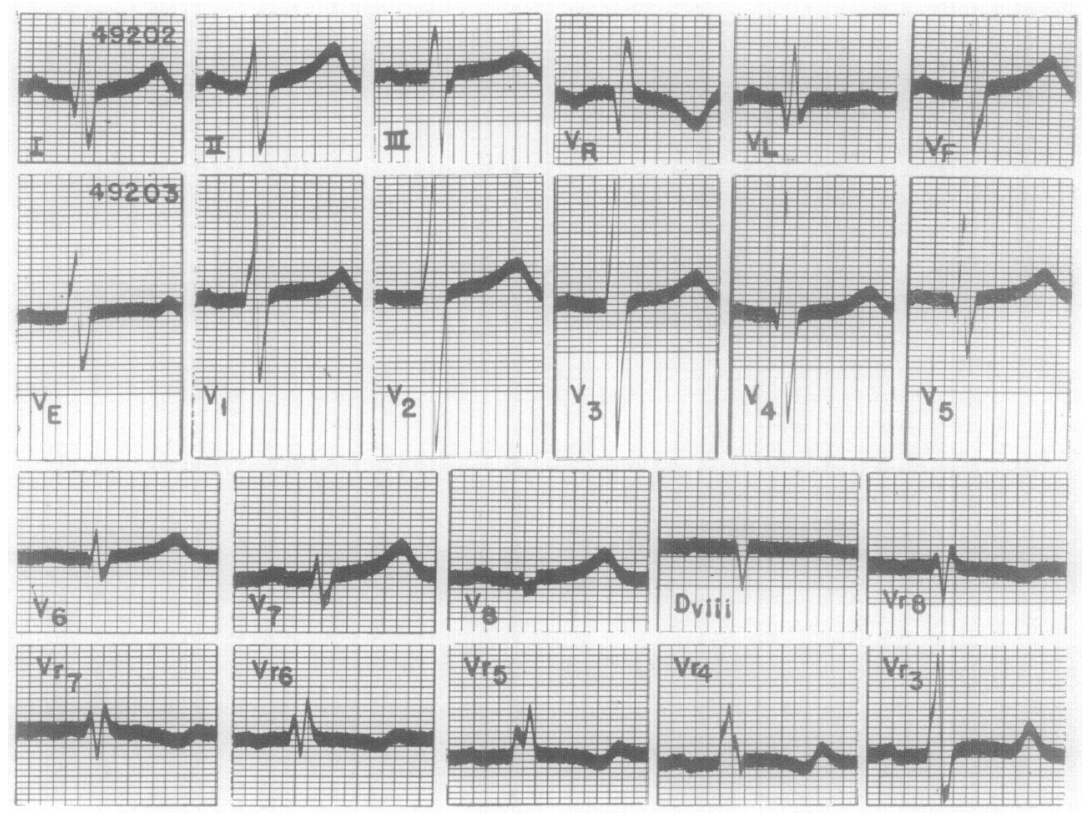

Fig. 9. - Incomplete right bundle branch block in a case of congenital cardiac anomaly (atrial septal defect or pulmonic stenosis). Transitional zone displaced to the right: $V_{r 3}, V_{r_{4}}$, etc., are leads from the right side of the chest corresponding to $V_{3}, V_{4}$, etc., from the left side. $V_{7}$ is a lead from the left posterior axillary line, $V_{8}$ a lead from the left back. Dviii is a lead from the eighth dorsal spine.

of the transitional zone in front, and transitional complexes are present in Lead $\mathrm{V}_{\mathrm{r} 3}$. These tracings display a very broad transitional zone, with extreme displacement of its boundaries to the left and to the right. They illustrate the value of additional leads from points to the right of the right sternal margin when the usual precordial leads fail to cross the transitional zone.

\section{INCOMPLETE RIGHT BUNDLE BRANCH BLOCK AND RIGHT VENTRICULAR HYPERTROPHY}

When incomplete right bundle branch block is associated with right ventricular hypertrophy there is characteristically a tall secondary $\mathrm{R}$ deflection in the leads from the right side of the precordium. The leads from the left side often show a small $\mathrm{R}$ deflection followed by a small $\mathrm{S}$ deflection. The pattern is, in general, similar to that seen in right ventricular hypertrophy uncomplicated by incomplete right bundle branch block. Those electrocardiograms 
AMERICAN HEART JOURNAL

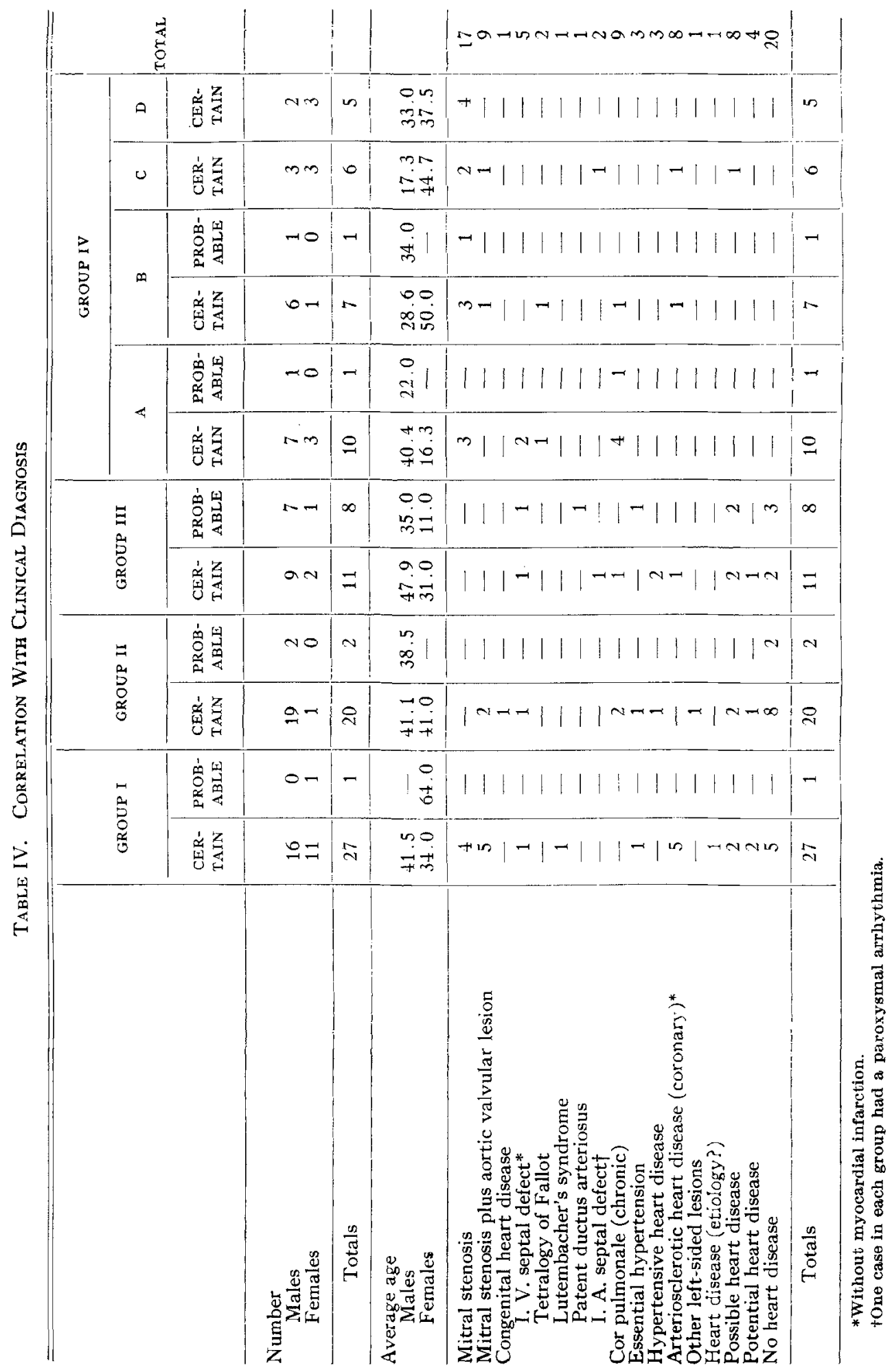


which displayed a tall $\mathrm{R}^{\prime}$ wave in Leads $\mathrm{V}_{1}$ and $\mathrm{V}_{2}$ were placed in Group IV $(A, B, C$, and $D)$. The various QRS configurations encountered are illustrated in Fig. $7(E, F, G$, and $H)$. In addition to changes suggestive of incomplete right bundle branch block, all of these patients showed definite right axis deviation in the limb leads. With one exception the clinical diagnoses made were consistent with the presence of right ventricular hypertrophy (Table IV).

A precordial electrocardiogram which is representative of Group IV, $\mathrm{A}$ is reproduced in Fig. 7,E. It was taken on Nov. 20, 1945. The patient was a man 22 years of age with physical signs typical of the tetralogy of Fallot. The standard limb leads show right axis deviation and large $\mathrm{P}$ waves in Lead II. The unipolar extremity leads indicate that the heart was in the vertical or semivertical position. Leads $V_{1}$ and $V_{E}$ display a small initial $R$ wave and a very tall $R^{\prime}$ deflection. The leads from the left side of the precordium, and

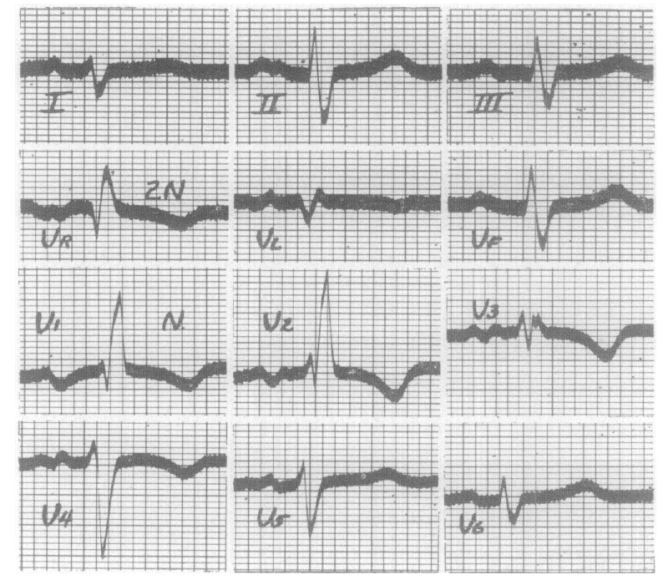

Fig. 10.-Incomplete right bundle branch block associated with right ventricular enlargement. The patient was a 42-year-old man with rheumatic mitral stenosis and aortic regurgitation. Note large secondary $R$ waves in Leads $V_{1}$ and $V_{2}$.

especially Lead $V_{6}$, show smaller QRS deflections, with $R$ and $S$ waves of nearly equal size. In this particular instance the transitional zone begins with Lead $\mathrm{V}_{2}$; it is not uncommon to find this zone displaced somewhat to the right in cases of the kind under consideration. The pattern is the reverse of that seen in incomplete right bundle branch block without right ventricular hypertrophy, with regard to the size of the $R^{\prime}$ wave in the leads from the right side of the precordium in comparison with that of the $R$ wave in the leads from the left side.

Another example of the tracings placed in Group IV is reproduced in Fig. 10. This electrocardiogram is that of a man, 42 years of age with rheumatic heart disease, mitral stenosis, and aortic regurgitation. Roentgenographic examination, including orthodiagraphy, showed cardiac enlargement, left auricular 
enlargement, and calcification of the mitral valve. Large deformed $P$ waves suggestive of auricular enlargement and consistent with the diagnosis of mitral stenosis are present in Leads I and II. The P-R interval measures 0.21 second and the QRS interval, 0.08 second. There are large $S$ waves in Leads I, II, and III, and a broad, late $R$ wave in Lead $V_{R}$. Since the potential variations of the left leg resemble those of the left side of the precordium, and the deflections of Lead $V_{L}$ are small, the heart was in the semivertical position. Leads $V_{1}$ and $V_{2}$ show a small initial $R$ wave followed a very tall $R^{\prime}$ deflection. The latter is a little larger in I ead $V_{2}$ than in Lead $V_{1}$. The leads from the left side of the precordium $\left(V_{5}\right.$ and $V_{0}$ ) display rather small QRS deflections with rather broad $S$ waves. The other precordial leads $\left(V_{3}\right.$ and $\left.V_{4}\right)$ exhibit complexes transitional in form between those found in the leads from the right, and those found in the leads from the left side of the precordium. The large secondary $R$ wave in the leads from the right side diminishes rather rapidly in the leads from points farther to the left, and there is no sign of it in Lead $V_{4}$. This is a fairly typical example of the pattern seen in the precordial leads when incomplete right bundle branch block is associated with right ventricular hypertrophy.

The electrocardiogram reproduced in Fig. 7,F was taken on Feb. 16, 1943. The patient was a man 35 years of age who had suffered since infancy from a chronic cough productive of foul sputum. There was a history of several attacks of "pneumonia" during the six years previous to the examination, and of increasingly severe dyspnea, upper abdominal pain, and slight edema of the ankles during the two weeks preceding the examination. His general health had been poor. Roentgenographic examination of the chest revealed widespread, patchy pneumonitis, perihilar infiltration, and thickening of the pleura at both apices. These findings were considered highly suggestive of bronchiectasis. The heart was moderately enlarged. The blood pressure was $110 / 74$. Clubbing of the fingers and toes and obvious acral cyanosis were present. The patient did not return for further studies.

The electrocardiogram shows slight right axis deviation, and unusually large $\mathrm{P}$ waves and inverted $\mathrm{T}$ waves in Leads II and III. The QRS interval measured 0.08 second in the limb leads. I eads $V_{1}$ and $V_{2}$ show double $R$ waves, indicating a delay in activation of the right ventricle. The $R^{\prime}$ deflection is relatively tall in Lead $V_{1}$ and measures about 9.5 millimeters. Lead $V_{E}$ shows a small initial $R$ wave followed by a deep $S$ deflection. The complexes of Lead $V_{2}$ are transitional in form between those of Lead $V_{1}$ and those of Lead $V_{3}$. The QRS complexes of the midprecordial leads $\left(V_{3}\right.$ and $V_{4}$ ) are of unusual outline. in that they consist of a small $\mathrm{R}$ wave followed by a deep $\mathrm{S}$ deflection, while those of Lead $V_{5}$ appear to be transitional in form between the complexes of I ead $V_{4}$ and those of I ead $V_{6}$. The $R$ wave of the latter is only slightly smaller than the $R^{\prime}$ deflection of Lead $V_{1}$ and is followed by a prominent $S$ wave.

Some of the features seen in this tracing are rather difficult to explain satisfactorily. The leads from the right side of the precordium are rather strongly suggestive of incomplete right bundle branch block, and the tall $\mathrm{R}^{\prime}$ deflection in Lead $V_{1}$, together with the clinical impression of cor pulmonale, makes it highly probable that a right ventricular hypertrophy was present. The factors re- 
sponsible for the QRS pattern seen in the midprecordial leads are not obvious, but this configuration indicates that the main electrical forces acting on the midprecordium had an anteroposterior direction. It seems probable that this pattern is the result of some peculiarity in the position of the heart which led to an unusual distribution of the areas on the surface of the chest to which the potential variations of the two ventricular surfaces were transmitted. It may be mentioned in this connection that the leads from the extreme right side of the precordium are from points relatively near the thick basal parts of the right ventricular wall, whereas those from the midprecordium are from points closer to the thinner central and apical parts of this wall. In animals, leads from the base of the right ventricle show large $R$ waves, while those from the central region and apex show small $R$ waves. It is possible that under some circumstances the precordial leads may be affected in the same way.

The tracing reproduced in Fig. 7,G is an example of those placed in Group IV, Class c. The patient was a 9-year-old boy who at the age of 7 had begun to tire easily, to become dyspneic, and to develop anorexia. There was no known episode of acute rheumatic infection. When he was 8 years old, a cardiac murmur was discovered. A few months later edema of the ankles developed, and during the following two weeks he was orthopneic. Two months prior to hospital admission, ascites, sufficient in amount to require two paracenteses, appeared, and was accompanied by nocturnal dyspnea. On examination, the heart was found to be greatly enlarged both to the right and to the left. A loud systolic and a rumbling diastolic murmur were heard at the apex, and there was a rather faint, short diastolic murmur along the left edge of the sternum. The blood pressure was 120/40. An orthodiagram and film studies of the chest showed generalized cardiac enlargement with a moderate degree of pulmonary congestion. There was pronounced diminution of the retrocardiac space as well as deformity of the anterior thoracic wall as a result of tremendous cardiac dilatation. The diagnosis was rheumatic heart disease, mitral stenosis, and aortic regurgitation, but the possibility of the presence of an interatrial septal defect could not be excluded.

The electrocardiogram taken on June 7, 1945, shows right axis deviation and a QRS interval of 0.10 second in the limb leads. The $P$ waves are unusually large and broad and suggest auricular enlargement. The leads from the right side of the precordium ( $V_{1}$ and $V_{2}$ ) and from the tip of the ensiform process $\left(V_{E}\right)$ display complexes of the kind we have described as characteristic of incomplete right bundle branch block plus right ventricular hypertrophy. The transition from complexes of the kind seen in the first to complexes of the kind seen in the last leads of the precordial series begins with Lead $V_{2}$ and ends with Lead $V_{5}$. Lead $V_{6}$ shows a very tall $R$ wave, which, again, is an unusual feature not easily explained.

The last set $(H)$ of precordial leads in Fig. 7 is a representative of Group IV, d. The patient was a 35-year-old man who was studied at the Iniversity Hospital in December, 1943. During the preceding three years he had had several episodes of hemoptysis following strenuous exertion. He liad been a "blue baby" and for many years his friends had commented on his blue color, 
and particularly on his blue-black lips. From childhood he had become purple on moderate exertion. He had been told on several occasions that there was something wrong with his heart, and had had clubbing of the fingers and toes as long as he could remember. Examination revealed moderate acral cyanosis. The precordial area was prominent. The heart was moderately enlarged to the left. At the apex there was a loud, low-pitched, coarse diastolic murmur ending in a snapping first sound. There were variations in the intensity of this sound. Along the left border of the sternum there was a faint, high-pitched diastolic murmur. The blood pressure was 104/70. The hemoglobin was 142 per cent. Roentgenographic examination showed pronounced enlargement of the pulmonary conus and the pulmonary vessels. The increase in the size of these vessels was so great as to lead to a suspicion of aneurysm of the pulmonary artery. There was also transposition of the thoracic aorta. The heart was moderately enlarged in all diameters, hut there was no evidence of atrial enlargement. The proper anatomic diagnosis was thought to be interatrial septal defect.

The electrocardiogram of Dec. 20,1943 , revealed that from time to time idioventricular rhythm was present, and that the rate of this rhythm was fast enough to cause $\mathrm{A}-\mathrm{V}$ dissociation. This accounts for the variations in the position of the $P$ wave in the illustration. Leads $V_{E}, V_{1}$, and $V_{2}$ were taken with the electrocardiograph operating at its normal sensitivity; the other precordial leads were taken with the instrument at one-half the normal sensitivity. The QRS interval measures 0.08 second in the limb leads. The leads from the right side of the precordium $\left(V_{1}\right.$ and $V_{2}$ ) show small initial $R$ deflections and tall $R^{\prime}$ waves similar to those we have described as characteristic of this group. The same QRS configuration is present in I.ead $V_{3}$, and a remnant of the primary $R$ can be seen at the base of the main upward deflection in Lead $V_{4}$. Besides a slight shift of the transitional zone to the left, the sequence of changes suggests that the secondary $\mathrm{R}$ wave moved toward the beginning of the QRS group and engulfed the primary $R$ wave as the exploring electrode was moved from right to left. The leads from the left side of the precordium display a prominent early $R$ deflection followed by a conspicuous $S$ wave. The transitional zone is not well defined, but the late $R$ wave of Leads $V_{1}, V_{2}$, and $V_{3}$ is replaced by an $S$ deflection in Leads $V_{4}, V_{5}$, and $V_{6}$.

The factors responsible for the large $\mathrm{R}^{\prime}$ deflection in the leads from the right side of the precordium in incomplete right bundle branch block associated with right ventricular hypertrophy are no doubt the same as those that give rise to the abnormally large QRS defections both in uncomplicated hypertrophy of the left and in uncomplicated hypertrophy of the right ventricle. In attempts to explain these abnormally large defections it has been suggested that: (1) Because the solid angle subtended at the exploring electrode by the extensive surface area of the hypertrophied ventricle is abnormally large, the effect of the enlarged ventricle upon the potential variations of this electrode is much the same as if it were moved closer to the epicardial surface. (2) In ventricular hypertrophy the cross-sectional area of each individual muscle fiber is increased. Increasing the cross-sectional area of a muscle fiber reduces its internal resistance, but leaves unchanged the external resistance in the circuits involved in excitation. 
Since the voltage drop in each part of the circuit is proportional to the ratio of the resistance of that part to the total resistance in the circuit, the effect of increasing the size of the fiber is to increase the magnitude of the potential variations over its external surface produced by the spread of the excitatory process.

Probably the increased voltage of the electrocardiographic deflections in ventricular hypertrophy is due to a combination of several factors. When incomplete right bundle branch block is associated with right ventricular hypertrophy, the increased voltage developed during activation of the free wall of the right ventricle, and perhaps during activation of the right half of the septum also, gives rise to the very tall secondary $R$ wave recorded in the leads from the right side of the precordium.

\section{INCOMPLETE RIGHT BUNDLE BRANCH BLOCK AND LEFT VENTRICULAR HYPERTROPHY}

In four of the cases of right bundle branch block which we studied, it was thought that the defect in conduction was complicated by electrocardiographic signs suggestive of left ventricular hypertrophy. There was one case of coarctation of the aorta (not included in our series of cases of incomplete right bundle branch block) in which the QRS interval measured 0.12 second. We suspected that in this instance incomplete right bundle branch block was associated with hypertrophy of the left ventricle. Since both the delay in conduction and the increased thickness of the free wall of the left ventricle would contribute to the duration of the QRS interval, it may be assumed that had the hypertrophy not been present the QRS interval would have been shorter. The electrocardiogram shows significant left axis deviation, and the heart was in the semihorizontal electrocardiographic position. The leads from the right side of the precordium show two $\mathrm{R}$ waves of rather small and nearly equal voltage, separated by a very deep $\mathrm{S}$ deflection. Those from the left side exhibit abnormally tall $\mathrm{R}$ waves and inverted $\mathrm{T}$ waves. The leads from the midprecordium display deflections of transitional form. In other words, the pattern is similar to that seen in left ventricular hypertrophy, apart from the evidence of delayed activation of the right ventricle.

\section{INCOMPLETE RIGHT BUNDLE BRANCH BLOCK ASSOCIATED WITH MYOCARDIAL. INFARCTION OR WITH PULMONARY EMBOLISM}

There were eleven cases in our series in which myocardial infarction had occurred. The sex distribution, types of infarcts, and other data are given in Table V. There is comparatively little difference, with regard to the configuration of the ventricular deflections of the electrocardiogram, between incomplete right bundle branch block associated with infarction and complete right bundle branch block associated with infarction. The latter has becn discussed in detail by Rosenbaum and others. ${ }^{7,9}$ Posterior infarction is recognized by the characteristic changes which it produces in Leads II, III, and $V_{F}$. Anteroseptal infarcts abolish the primary $R$ wave in the leads from the right side of the pre- 
cordium, but the $\mathrm{R}^{\prime}$ wave is unusually large in these leads because of the reduction of the opposing left ventricular forces incident to the infarction.

There were two cases in which incomplete right bundle branch block was associated with pulmonary embolism. They are mentioned here for the sake of completeness. These cases will be discussed in detail in a subsequent article.

Table V. Incomplete Right Bundle Branch Block and Myocardial Infarction

\begin{tabular}{|c|c|c|}
\hline & CERTAIN & PROBABLE \\
\hline $\begin{array}{c}\text { Number } \\
\text { Males } \\
\text { Females }\end{array}$ & $\begin{array}{l}7 \\
1\end{array}$ & $\begin{array}{l}3 \\
0\end{array}$ \\
\hline Total & 8 & 3 \\
\hline $\begin{array}{c}\text { Average age } \\
\text { Males } \\
\text { Females }\end{array}$ & $\begin{array}{l}51.6 \\
59.0\end{array}$ & 54.3 \\
\hline $\begin{array}{l}\text { Anteroseptal infarct } \\
\text { Extensive anterior infarct } \\
\text { Small anterior infarct } \\
\text { Posterior infarct }\end{array}$ & $\begin{array}{l}4 \\
2 \\
1 \\
1\end{array}$ & $\begin{array}{l}0 \\
0 \\
0 \\
3\end{array}$ \\
\hline Total & 8 & 3 \\
\hline
\end{tabular}

CORRELATION OF ELECTROCARDIOGRAPHIC AND CLINICAL DATA

Table VI gives the age and sex incidence of incomplete right bundle branch block in our series of cases. It will be noted that the incidence is relatively high in the first decade of life. This is obviously due to the frequency of this conduction defect in congenital heart disease. In the second decade the number of cases is smaller, but thereafter it rises gradually, and the greatest frequency occurs in the fourth, fifth, and sixth decades. There is a preponderance of males over females in the ratio of approximately $3: 1$.

Table Vi. Incidence According to Decades

\begin{tabular}{l|r|r|r}
\hline \multicolumn{1}{c|}{ DECADE } & MALES & FEMALES & TOTAL \\
\hline First & 10 & 1 & 11 \\
Second & 3 & 3 & 6 \\
Third & 8 & 4 & 12 \\
Fourth & 18 & 4 & 22 \\
Fifth & 8 & 5 & 13 \\
Sixth & 13 & 0 & 21 \\
Seventh & 9 & 1 & 9 \\
Eighth & 2 & 26 & 97 \\
\hline Totals & 71 & 0 & 9 \\
\hline
\end{tabular}

Number of cases, 96 . Highest age, 79 years.
Lowest age, 19 months. Average age, 40.8 years.
Average age in females, 41.7 years.

A verage age in males, 39.9 years. 
Table IV gives the distribution with respect to clinical diagnosis, sex, and age of the patients included in the first four groups. This table has been referred to previously in connection with the discussion of incomplete right bundle branch block associated with right ventricular hypertrophy.

It is interesting to note that twenty of the patients showed no evidence of heart disease. In eight additional instances a diagnosis of possible heart disease, and in four more a diagnosis of potential heart disease was made. There were also three cases of essential hypertension in which evidence of cardiac involvement was not elicited. Consequently, there were in all, thirty-one cases in which a definite diagnosis of heart disease could not be made. It is, therefore, hazardous to make a clinical diagnosis of heart disease on the basis of the electrocardiographic findings alone in cases in which the only demonstrable abnormality is incomplete right bundle branch block. On the other hand, the remaining patients had serious heart disease. There were forty-seven with lesions involving the right and thirteen with lesions involving the left side of this organ.

\section{DISCUSSION AND CONCLUSIONS}

Since most of our material has been discussed as it has been presented, there is little need for further emphasis on the great majority of points, except to indicate what we consider the criteria necessary for diagnosis.

Incomplete right bundle branch block should be suspected in every case in which there is a relatively broad $S$ wave in Lead I, especially if the QRS interval is longer than in the average normal electrocardiogram. In our cases of incomplete right bundle branch block the QRS interval ranged from 0.08 to 0.115 second.

The presence of a primary and a secondary $R$ wave or a prominent late $R$ wave in Lead $V_{R}$ is relatively common in cases of incomplete right bundle branch block, but is also frequent when this conduction defect is not present and is not a reliable sign.

The presence of an early $R$ deflection and a late $R$ ' deflection in the leads from the right side of the precordium, especially if both deflections are present in both Lead $V_{1}$ and Lead $V_{E}$, is diagnostic. If suggestive changes are present in Lead $V_{1}$, or in Leads $V_{1}$ and $V_{2}$, it is advisable to take additional leads from the right side of the chest $\left(V_{r_{3}}\right.$ and $\left.V_{r 4}\right)$ or to carry out an even more extensive exploration of the heart field in order to confirm the diagnosis.

When right ventricular hypertrophy and incomplete right bundle branch block are associated, there is, in addition to the changes described, a very tall $\mathrm{R}^{\prime}$ deflection in the leads from the right side of the precordium. This deflection usually exceeds $10 \mathrm{~mm}$. in height. The leads from the left side of the precordium often show rather small $\mathrm{R}$ deflection's and deep $\mathrm{S}$ waves. However, electrocardiograms representing this combination may exhibit a variety of patterns. Four of these have been described. 


\section{REFERENCES}

1. Rothberger, C. J., and Winterberg, H.: Experimentelle Beitrage zur Kenntnis der Reizleitungsstörungen in den Kamern des Saugetierherzens, Ztschr. f. d. ges. exper. Med. $5: 264,1917$.

2. Wilson, F. N., and Herrmann, G. R.: An Experimental Study of Incomplete Bundle Branch Block and of the Refractory Period of the Heart of the Dog, Heart 8:230, 1921.

3. Wilson, F. N., Johnston, F. D., Rosenbaum, F. F., Erlanger, H., Kossmann, C. E., Hecht, H., Cotrim, N., Menezes de Olivera, R., Scarsi, R., and Barker, P. S.: The Precordial Electrocardiogram, Am. Hear' J. 27 :2, 1944.

4. Wilson, F. N., Hill, I. G. W., and Johnston, F. D.: The Interpretation of the Galvanometric Curves Obtained When One Electrode is Distant From the Heart and the Other Near or in Contact With Its Surface. II. Observations on the Mammalian Heart, AM. Heart J. 10:176, 1934.

5. Battro, A., and Bidoggia, H.: Endocardiac Electrocardiograms Obtained by Heart Catheterization, Am. HeArT ]. 33:604, 1947.

6. Wilson, F. N., Macleod, A. G., and Barker, P. S.: The Interpretation of the Initial Deflections of the Ventricular Complex of the Electrocardiogram, Am. HEART J. 6:5, 1931.

7. Rosenbaum, F. F., Erlanger, H., Cotrim, N., Johnston, F. D., and Wilson, F. N.: The Effects of Anterior Infarction Complicated by Bundle Branch Block Upon the Form of the QRS Complex of the Canine Electrocardiogram, AM. HEART J. 27:783, 1944.

8. Wilson, F. N., Macleod, A. G., and Barker, P. S.: The Determination and the Significance of the Areas of the Ventricular Deflections of the Electrocardiogram, AM. HEART J. $10: 46,1934$

9. Wilson, F. N., Rosenbaum, F. F., Johnston, F. D., and Barker, P. S.: The Electrocardiographic Diagnosis of Myocardial Infarction Complicated by Bundle Branch Block, Arch. d. Inst. de Cardiol. de Mexico. 14:3, 1945. 